\title{
Exploring barriers to Sexual Transmitted Infections and HIV testing among young Black Sub-Sahara African (BSSA) communities in Diaspora, UK.
}

\begin{tabular}{|r|l|}
\hline Journal: & Journal of Public Mental Health \\
\hline Manuscript ID & JPMH-05-2020-0038.R2 \\
\hline Manuscript Type: & Original Research Paper \\
\hline Keywords: & $\begin{array}{l}\text { Black sub-Sahara African, HIV, Risk behaviour., Sexual transmitted } \\
\text { infection }\end{array}$ \\
\hline
\end{tabular}


The four phases of data analysis in The Silences Framework

\section{Fig 1}

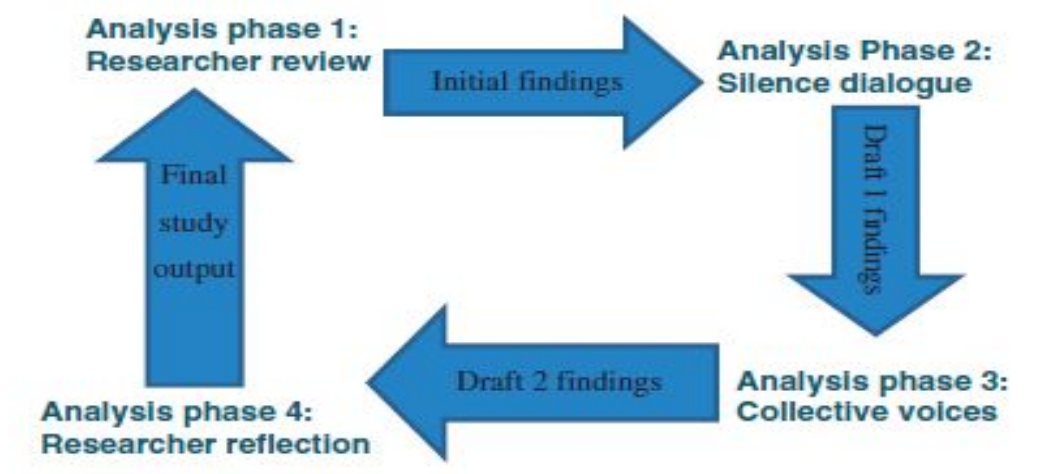

Representation of the phases of analysis (Serrant-Green, 2011) 


\title{
Exploring barriers to Sexual Transmitted Infections (STIs) testing among young Black Sub-Sahara African (BSSA) communities in Diaspora, UK
}

\begin{abstract}
Purpose of this paper

Sexual transmitted infections are associated with high stigma leading to poor sexual health seeking behaviour and mental health problems. Although HIV prevention has generally been successful in many communities across the world, statistics for young people has remained relatively low especially among most affected communities like the black sub-Sahara African (BSSA) communities. This research sought to explore the barriers to sexual transmitted infections and HIV testing among young BSSA communities living in the UK
\end{abstract}

\section{Design/methodology/approach}

The research study utilised an explorative qualitative approach. 6 focus groups comprising of ten people each $(\mathrm{N}=60)$ and 12 one to one follow up interviews were held with the research participants. Two one to one follow up interviews were held from each focus group $(\mathrm{N}=12\}$

\section{Findings}

The research found that Perceived risk taking, Perceived HIV test embarrassment, Sexual health professionals' attitudes, Perceived HIV as death sentence, Limited educational awareness and General HIV stigma prevented research participants from testing and impacted on their mental health wellbeing.

\section{What is original/value of paper}

There is need to increase sexual health and mental health education awareness among young BSSA communities. More importantly culturally sensitive interventions to reduce the impact of HIV stigma need to be rolled out in different diverse communities. This research is the first of its kind to look at barriers affecting young BSSA in accessing sexual health testing services in UK.

\section{Key words}

Black sub-Sahara African, HIV, Risk behaviour, Sexual transmitted infections

\section{Introduction}

Human immunodeficiency virus (HIV) which leads to Acquired Immune Deficiency Syndrome (AIDS) if not treated is associated with high levels of stigma in many communities leading to poor sexual health seeking behaviour among communities (Desmennu, Titiloye \& Owoaje, 2018). HIV prevention and treatment has extensively been achieved in many parts of the world, through HIV testing which has been considered important and cost-effective throughout research (Muture et al, 2011).HIV testing rates for young people worldwide are relatively low compared to adults and this is due to numerous inhibiting factors (Kabiru et al, 2010). Nonetheless, Singhal, Naswa \& Marfatia (2009) assert that adolescent HIV/AIDS is a separate epidemic and needs to be handled and managed separately from adult HIV putting into consideration the needs and aspirations of young people. Research and literature dominating the subject of HIV and sexual health seeking behaviour has always favoured the adult population leaving gaps in the sexual health of young people (18-24 years) especially those 
from BSSA background which is the target of discussion in this research study. The available literature on young people and access to HIV services does not include young BSSA people as they are relatively new on the British demography.

Health professionals have expressed concern on the sexual health risk behaviour experienced by young people resulting in increase of HIV/STIs transmissions (Logie et al, 2017). These behaviours are characterised by inconsistent condom use, having multiple sex partners, intravenous drug use, and use of alcohol and other substances that impair judgment about risk while impacting on their mental health wellbeing. In addition, Lunn et al (2017) also suggest that when young people combine these behaviours their risk of contracting STIs and HIV increases. It is important to acknowledge that levels and types of STIs and HIV risks changes in relation to different cultural and environmental factors (McNairy, 2014)

Gupta el al \& El Sadr (2008) argue that in some ethnic groups and culture, sexual health risk behaviour among adolescence may be a result of inconsistency in condom use. Furthermore, there is limited research among young people and their access to sexual health and HIV services including why risky sexual behaviour persists among young people (Mberu, 2008). Moreover, there is no clear evidence on the motivation behind multiple partners or non-use of protection like condoms. Lack of appropriate reproductive, sexual health and HIV information has been suggested in contributing to adolescence sexual health and HIV risk (Kajula et al, 2014). In some communities, negotiating the use of condoms during sexual activities can be equated to mistrust of the partner (East, Jackson, O'Brien, \& Peters, 2007). This has discouraged many young people from negotiating condom use with their partners.

Furthermore, gender plays an important role in vulnerability to sexual health risk behaviour. Amuyunzu-Nyamongo et al (2005) argue that female adolescents may find it difficult to negotiate a condom especially after receiving gifts or money from a sexual partner. This can be exacerbated by poor economic outlook especially in low and middle-income countries. Tschann (2010) also asserts that at times young male adolescents may insist on not using condoms due to the perception and beliefs that condoms hinder sexual sensation. Such perceptions are normally discussed in young people circles thereby entrenching a socially constructed notion to condom resistance (Tschann et al, 2002). In addition, further reasons that may prevent condom use include sheer dislike of condoms, embarrassment and fear of purchasing condoms from adult service providers normally caused by health professionals' disapproval attitudes (Nalwadda, et al, 2010). These factors can be argued to be part of the larger perceptions shaping beliefs, notions and perspectives of young people towards sexual health and HIV health seeking behaviour. Moreover, HIV programs that are targeted at adolescents to raise awareness of HIV/STIs are often based on expanding their knowledge that leads to change in their sexual behaviour (Norbu \& Mukhia, 2013). However, it has been argued in some studies that there is lack of association between knowledge and behaviour. For example, young people in the UK have access to sexual health services and information that is provided through educational institutions such as universities and schools, however these young people remain among the highest group in the country that still engages in risky sexual behaviour (Chanakira et al, 2014).

The late 90s saw the emergence of the Black Sub-Sahara African communities on the British demography owing to civil strife and economic meltdown (Timberlake, 2013). Two thirds of people of people living with HIV in the world today are in Sub-Sahara African countries (Lecher et al, 2016). Many HIV researches that have been undertaken in BSSA communities have involved adults and very 
few of them have incorporated young people. In light of the above assertions, this study was set out to explore barriers to HIV testing among BSSA young people (18-24 Years) living in diaspora.

\section{Methodology}

This research study utilised an explorative qualitative approach to explore the barriers to sexually transmitted infections and HIV testing among BSSA young people. 6 focus groups and 12 one to one follow up interviews were held with young BSSA men and women living in the West Midlands region. Each of the six focus groups was made up of 10 young people with balanced gender distribution $(\mathrm{N}=60)$. Two one to one follow up interviews were held from each focus group $(\mathrm{N}=12)$. The focus groups lasted for two hours while the one to one follow up interviews lasted for forty-five minutes. A purposive sampling was employed to recruit research participants. Participants were recruited through community organisations and faith groups. The researcher initially contacted the organisations managers who gave information to the young people. The researcher contacted only those, who expressed interest to take part in the research study.

An interview schedule aided by prompts was used to guide the focus group discussions. Following completion of the focus group discussions, a further interview schedule for one to one follow up interviews was developed to explore issues raised during the focus group discussions requiring further exploration.

On completion of the interviews, all transcripts were inputted into qualitative data management software, NVIVO. A thematic analysis guided by the four phases of The Silences Framework (TSF) was used to analyse data from focus groups and one to one follow up interviews (Serrant-Green, 2011). TSF was utilised here because it provides a clear analytical process for qualitative data. In phase one the researcher analysed the data from focus groups and one to one follow up interviews into themes. In phase two the researcher went back to confirm the output of phase one with research participants. At this point, the research participants confirmed or refuted the data from phase one. In phase three, the researcher used a group that mirrored the research participants but did not participate in the research study, to confirm the analysis from phase two. Finally, in phase four the researcher analysed the data from phase three to make the final output of the study. See figure 1 below showing the four explained phases.

The four phases of data analysis in The Silences Framework

The study was granted ethical approval by Nottingham Trent university ethics committee. All research participants completed a consent form, which gave permission to withdraw from the study at any time without giving any reason.

\section{Results}

Following the analysis of data some six themes were generated and supported by extracts from the focus groups and one to one follow up interviews. The generated themes included Perceived risk 
taking, Perceived HIV test embarrassment, Sexual health professionals' attitudes, Perceived HIV as death sentence, Perceived limited Education awareness and HIV stigma.

\section{Perceived risk taking}

The young people felt that the older adults within BSSA communities viewed them as risk takers and were likely to be affected by sexual transmission infections and HIV. In the light of this, young people are reluctant to take tests as they fear confirming this perceived notion.

Adults always assume that I am a risk taker and tell me that I will die from HIV. At the same time, they do not advise you what to do. I am tired of this talk every day. I wish they also value my perception of danger when I am dealing with HIV especially at this point and time when talking about HIV and let alone having it is highly stigmatised. (A young man aged 18)

There is a belief among the elderly that we are so risk taking and we are not aware of the dangers of HIV. Most of them think that we do not believe in testing. They think we have a poor perception of what is safe sex and I think this is driven by the transition from one culture to another, which most adults in our African communities are undergoing. It then makes you to feel scared if you think about testing. (A young woman aged 20)

\section{Perceived HIV test embarrassment}

The young people felt embarrassed to take an HIV test in the presence of parents or other older people because they felt that the community holds the notion that anyone taking a test has been doing bad things like sleeping around. There was also a feeling that the parents needed to change the way they viewed people who were taking an HIV test.

I find it very embarrassing to take an HIV test in the presence of other people because they will laugh at you. The problem is once you take a test, they start to think that there is something bad that you have done like sleeping around which according to my culture is really embarrassing. (A young man aged 22)

It really depends on who you are taking the test with I feel I will not be comfortable to take a test in the presents of my dad and mum. However, my friends would not care in fact they would encourage me to take the test. I feel that my mum and dad need to change the way they view people who go to the clinic for an HIV test (A young woman aged 23)

\section{Sexual Health professionals' attitude}

\section{The young people also felt that the questions that sexual health professionals asked them made them feel uncomfortable and sometimes discouraged them form taking an HIV test.}

Sometimes the way you are asked questions by the sexual health professionals is very embarrassing. They look at you as though you have committed a crime, at times I just think why I come to this clinic.? But the point is I need to be treated; if I do not come, I will definitely ruin my life (A young man aged 24)

It is so embarrassing when you can clearly see that the staff in the clinic are talking about you and you cannot do anything. You can clearly hear some staff saying that look at that young boy is he is coming for treatment. I definitely feel like I will not come back again if I need treatment. It seems as though there is very high HIV stigma in treatment centres. (A young woman aged 18) 


\section{Perceiving HIV as Death Sentence}

The young people felt that being HIV positive is highly stigmatised and viewed as a death sentence in their communities. This leaves the young people with a divided mind on whether to take a test or to avoid it.

This is not my perception but many people I have interacted with seem to confirm that once someone is HIV positive, they are like on death role. Many people say a lot of information some of it is not even true I suppose. This leaves us young people with divided mind as to whether HIV is a death sentence, or it is just stigma. (A young man aged 21)

From what I hear from people, I would not like to pick HIV. I think all my friends will run away from me. Every time I take a test my heart will be pouncing fearing that the result might come back positive and I will not know what to do, it is really confusing I feel that more information is needed (A young woman aged 19)

Perceived Limited Educational Awareness

The young people felt that there was very limited information to make them aware of HIV. They also felt that there was need to have HIV programmes that were targeted towards young people.

I just feel that there is very limited information about HIV especially targeted at young people. Most of the information and initiatives are meant for old people. The young people are starved of the information; more programmes are needed to raise HIV awareness (A young man aged 22)

Some of the information coming from the communities lacks to be challenged. There is need to challenge the voice of stigma that has prevented many people from accessing HIV testing because of the myths associated with it I just feel that more money need to be channelled in to the young people $s^{\prime}$ work to improve the situation.(A young woman aged 18)

\section{HIV Stigma}

The young people felt that there was generally stigma against people who are HIV positive and that it discouraged the affected people to access HIV services.

There is a lot of stigma against people with HIV. This sometimes prevents people from accessing HIV and sexual health services. I feel that more programmes targeting HIV stigma need to be rolled out into the communities. (A young man aged 23)

I think HIV stigma will never go away as long as we are not open to each other. The BSSA communities are deeply divided on how to deal with this issue. More programmes are necessary. People need to have a spirit of togetherness to make sure that they get rid of HIV stigma (A young woman aged 21)

\section{Discussion}

The notion of blaming young people as being less informed about an issue and likely to end up in disadvantaged situations is not new among communities (Scott \& Steinberg, 2002). In light of this notion, this study found out that young BSSA people felt that people perceived as old viewed them as risk takers and were likely to be affected by sexual transmitted infections and HIV. This belief made 
the young people feel vulnerable and reluctant to test as they felt that if the test came back positive, this would only serve to confirm that they are risk takers as perceived by their elders. Furthermore, this notion may affect the mental health and well-being of young BSSA people as some may feel pressurised and stressed. It is therefore important that young people and their elder counterparts engage in an open, purposeful, and genuine dialogue about sexual health and HIV issues including the importance of taking up tests and treatment (Chandler, 2011). This will help to clear away the suspicion that has always existed between the two groups and help in building resilience towards uptake of sexual health and HIV services among BSSA young people.

Uptake of sexual health and HIV services among BSSA communities is viewed as a sign of promiscuity and embarrassment (Nyashanu, 2017). Although this is not explicitly implied, it is silently shared and confirmed in various quarters of the BSSA communities. It is this silently shared notion labelling people who utilise sexual health and HIV services as promiscuous that discourages young BSSA people from taking tests for both HIV and sexual transmitted infections. Furthermore, this inability to take tests because of community beliefs may end up stressing the young people. There is a need to come up with culturally friendly interventions that would challenge this silently shared sexual health and HIV testing stigma among BSSA communities (Sin \& Lyubomirsky, 2009). Such an intervention would empower young people and encourage them to view testing as a personal benefit that should not be to or impeded by secondary issues like perceived negative views from the community about the issue.

The attitudes of health professionals play a very important role in encouraging the utilisation of services by clients (Pickles, et al 2011). In this study some young people felt that the attitudes of the staff at sexual health testing and treatment centres discouraged them from utilising testing services for sexual health and HIV. The young people felt that although this was not verbally said the gaze or look that they got from professionals had blaming connotations (Sommer et al, 2001). The perceived feeling of blame can have an impact on the mental health wellbeing of young people. It is important that professionals working with patients in highly sensitive set-ups like sexual health and HIV testing are adequately trained and supported especially where they are dealing with clients from different cultural backgrounds where certain actions may be interpreted differently. Furthermore, it is important that young people are assured and supported by the service to build confidence and trust through open interaction that allows young people to ask questions and give comments about issues of concern. This can only be made possible by the proactiveness of the service in creating a conducive and welcoming atmosphere.

For many years being HIV positive was viewed as a death sentence in many communities including the BSSA communities (Matic et al, 2006). Although the discovery of quality HIV therapy saw improvements in treatment, this did not change the perceptions and notions that many communities held about being 
HIV positive. In this study, the BSSA young people felt that the BSSA communities held the notion that being HIV positive was equivalent to a death sentence and for that reason, many young people did not want to go for an HIV test. It therefore follows that young people diagnosed with HIV are more likely to be affected by mental health problems owing to the stigma held by BSSA communities towards HIV. It is important that communities need to be educated about the improvements in HIV treatment including the changes in recovery rate. This should then be used as a way of encouraging people to take a HIV test and avoid health complications in future.

Health education and awareness is very important in reducing new infections and reinfections of any disease or condition (Keating, Meekers \& Adewuyi, 2006). In this study the young people indicated that there was little health education and awareness targeted at young people. However, most of the health awareness and education available on HIV targeted older people. It is therefore important that the sexual health promotion service puts out health education and awareness that is aimed at all age groups within the population including the young people.

HIV stigma manifests and present in many forms thereby reducing the uptake of HIV services among communities (Golub \& Gamarel, 2013). In this study all the young people who took part acknowledged that HIV stigma was one of the reasons why young people were not testing. There is a need to come up with more initiatives to reduce HIV stigma and increase testing among the general population and young people in particular. In doing so sexual health and HIV professionals should come up with interventions that are culturally friendly towards a wide range of populations that make up the British demography.

\section{Limitations of the study}

This was a qualitative study looking at barriers to sexually transmitted infections and HIV testing; research encompassing both qualitative and quantitative paradigms will need to be undertaken in future. The research was also restricted to the English West midlands region while there are a number of BSSA communities living elsewhere in the UK research representative of all regions with BSSA communities need to be undertaken.

\section{Implication for sexual health professionals}

Sexual health professionals need to consider the needs of young people affecting their health seeking behaviour. There is need for culture competency training among sexual health professionals to enable them to deal with the diverse needs of their patients. More sexual health and HIV awareness targeted at young people from BSSA communities needs to be undertaken.

\section{Recommendations}

More research is needed to explore the sexual health and HIV needs of new communities like the BSSA communities. More services targeting young people with user-friendly interventions need to be developed and rolled out.

\section{Conclusion}


There is need to increase sexual health and HIV health education awareness among young BSSA communities. More importantly culturally sensitive interventions to reduce HIV stigma and increase uptake of sexual health and HIV services need to be rolled out in different diverse communities.

\section{Funding}

No funding was received for this research.

\section{References}

Amuyunzu-Nyamongo, M., Biddlecom, A. E., Ouedraogo, C., \& Woog, V. (2005). Qualitative evidence on adolescents' views of sexual and reproductive health in Sub-Saharan Africa. Occasional Report, 16.

Chanakira, E., O'Cathain, A., Goyder, E. C., \& Freeman, J. V. (2014). Factors perceived to influence risky sexual behaviours among university students in the United Kingdom: a qualitative telephone interview study. BMC public health, 14(1), 1055.

Chandler, C. L. (2011). Creating a different international HIV response for young people. Global public health, 6(sup3), S344-S356.

Desmennu, A. T., Titiloye, M. A., \& Owoaje, E. T. (2018). Behavioural risk factors for sexually transmitted infections and health seeking behaviour of street youths in Ibadan, Nigeria. African health sciences, 18(1), 180-187.

East, L., Jackson, D., O'Brien, L., \& Peters, K. (2007). Use of the male condom by heterosexual adolescents and young people: Literature review. Journal of Advanced Nursing, 59(2), 103-110.

Golub, S. A., \& Gamarel, K. E. (2013). The impact of anticipated HIV stigma on delays in HIV testing behaviors: findings from a community-based sample of men who have sex with men and transgender women in New York City. AIDS patient care and STDs, 27(11), 621-627.

Gupta, G. R., Parkhurst, J. O., Ogden, J. A., Aggleton, P., \& Mahal, A. (2008). Structural approaches to HIV prevention. The Lancet, 372(9640), 764-775.

Kabiru, Caroline W., Nancy Luke, Chimaraoke O. Izugbara, and Eliya M. Zulu. "The correlates of HIV testing and impacts on sexual behavior: evidence from a life history study of young people in Kisumu, Kenya." BMC Public Health 10, no. 1 (2010): 412.

Kajula, L. J., Sheon, N., De Vries, H., Kaaya, S. F., \& Aarø, L. E. (2014). Dynamics of parent-adolescent communication on sexual health and HIV/AIDS in Tanzania. AIDS and Behavior, 18(1), 69-74. 
Keating, J., Meekers, D., \& Adewuyi, A. (2006). Assessing effects of a media campaign on HIVIAIDS awareness and prevention in Nigeria: results from the VISION Project. BMC Public health, 6(1), 123.

Lecher, S., Williams, J., Fonjungo, P. N., Kim, A. A., Ellenberger, D., Zhang, G., ... \& Borget, M. Y. (2016). Progress with scale-up of HIV viral load monitoring - seven sub-Saharan African countries, January 2015-June 2016. Morbidity and Mortality Weekly Report, 65(47), 1332-1335.

Logie, C. H., Lacombe-Duncan, A., Brien, N., Jones, N., Lee-Foon, N., Levermore, K., ... \& Newman, P. A. (2017). Barriers and facilitators to HIV testing among young men who have sex with men and transgender women in Kingston, Jamaica: a qualitative study. Journal of the International AIDS Society, 20(1), 21385.

Lunn, M. R., Cui, W., Zack, M. M., Thompson, W. W., Blank, M. B., \& Yehia, B. R. (2017). Sociodemographic characteristics and health outcomes among lesbian, gay, and bisexual US adults using Healthy People 2020 leading health indicators. LGBT health, 4(4), 283-294.

Matic, S., Lazarus, J. V., \& Donoghoe, M. C. (Eds.). (2006). HIVIAIDS in Europe: moving from death sentence to chronic disease management. WHO Regional Office Europe.

Mberu, B. U. (2008). Protection before the harm: The case of condom use at the onset of premarital. African Population Studies, 23(1).

McNairy, M. L., \& El-Sadr, W. M. (2014). A paradigm shift: focus on the HIV prevention continuum. Clinical Infectious Diseases, 59(suppl_1), S12-S15.

Muture, B. N., Keraka, M. N., Kimuu, P. K., Kabiru, E. W., Ombeka, V. O., \& Oguya, F. (2011). Factors associated with default from treatment among tuberculosis patients in Nairobi province, Kenya: a case control study. BMC public health, 11(1), 696.

Nalwadda, G., Mirembe, F., Byamugisha, J., \& Faxelid, E. (2010). Persistent high fertility in Uganda: young people recount obstacles and enabling factors to use of contraceptives. BMC public health, 10(1), 530.

Norbu, K., \& Mukhia, S. (2013). Assessment of knowledge on sexually transmitted infections and sexual risk behaviour in two rural districts of Bhutan. BMC public health, 13(1), 1142.

Nyashanu, M. (2017). Beliefs and Perceptions in the construction of HIV stigma and sexual health seeking behaviour among Black sub-Sahara African (BSSA) communities in Birmingham, UK.

Pickles, K. J., Rhind, S. M., Miller, R., Jackson, S., Allister, R., Philp, J., ... \& Mellanby, R. J. (2011). Potential barriers to veterinary student access to counselling and other support systems: perceptions of staff and students at a UK veterinary school. Veterinary Record, vetrec-2011.

Scott, E. S., \& Steinberg, L. (2002). Blaming youth. Tex. L. Rev., 81, 799.

Sommer, K. L., Williams, K. D., Ciarocco, N. J., \& Baumeister, R. F. (2001). When silence speaks louder than words: Explorations into the intrapsychic and interpersonal consequences of social ostracism. Basic and Applied Social Psychology, 23(4), 225-243.

Serrant-Green, L. (2011). The sound of 'silence': a framework for researching sensitive issues or marginalised perspectives in health. Journal of Research in Nursing, 16(4), 347-360.

Sin, N. L., \& Lyubomirsky, S. (2009). Enhancing well-being and alleviating depressive symptoms with positive psychology interventions: A practice-friendly meta-analysis. Journal of clinical psychology, 65(5), 467-487. 
Singhal, P., Naswa, S., \& Marfatia, Y. S. (2009). Pregnancy and sexually transmitted viral infections. Indian journal of sexually transmitted diseases and AIDS, 30(2), 71.

Timberlake, L. (2013). Africa in crisis: The causes and cures of environmental bankruptcy. Routledge.

Tschann, J. M., Adler, N. E., Millstein, S. G., Gurvey, J. E., \& Ellen, J. M. (2002). Relative power between sexual partners and condom use among adolescents. Journal of Adolescent Health, 31(1), 17-25. 